\title{
Kleine Mitteilungen
}

\author{
Bemerkungen zu der Arbeit „Die Epithelzellmembran und ihre \\ Veränderungen" von 0 . B. Lepeschinskaja \\ Von M. Gutstein
}

Eingegangen am 16. Mai 1930

Die Behauptung Lepeschinskajas ${ }^{1}$ ), daß der Nachweis der Zellmembran mittels Tannin ihr zuerst gelungen ist, muß ich energisch in Abrede stellen. $\mathrm{Zu}$ dieser Meinung konnte die Autorin nur auf Grund ungenügenden Studiums der Literatur kommen.

Der Sachverhalt ist nämlich der folgende: Im Jahre 1924 (X. Kongreß der Deutschen Vereinigung für Mikrobiologie, 12. bis 14. Juni 1924 zu Göttingen) habe ich eine allgemeine Methode zum Nachweis der Membrander Bakterien und Hefezellen bekannt gegeben, die in der Beizung (nicht Fixierung) der Ausstriche mit Tannin und Nachfärbungen mit basischen Farbstoffen besteht (Zentralbl. f. Bakt. 93, H. 1/4, und 93, H. 6, 1924). In demselben Jahre habe ich in einem Vortrag in der Gesellschaft f. Pathol. u. Anatomie zu Berlin (11. Dezember 1924, Klin. Woch., 1925, Nr. 12, S. 568) über den Nachweis der Membran aller tierischen Zellen mittels der Tanninmethode und anderer Färbeverfahren berichtet. Den färberischen Nachweis der Erythrocytenmembran mittels Tannin und mehrerer anderer Färbemethoden habe ich 1925 (XI. Kongreß der Deutschen Vereinigung für Mikrobiologie, 24. bis 26. September 1925, Zentralbl. f. Bakt. 97, Beiheft) bekanntgegeben, während die ausführlichen Publikationen erst später erschienen sind.

Die Arbeit Lepeschinskajas über die Erythrocytenmembran ist 1925 erschienen (Fol. Haemat. 34, H. 1), in der aber nirgends darauf hingewiesen wird, dał3 deren Resultate bereits 1923 in U.S.S.R. erschienen wären.

Unrichtig ist auch die Behauptung Lepeschinskajas, ich hätte die Zellmembran nur als Grenzlinie aufgefaßt. Vielmehr habe ich wiederholt darauf hingewiesen (Zentralbl. f. Bakt. 93 und Abt. Ref., 78, S. 565, Fol. Haemat. 33, S. 192), daß die Zellen eine Hülle besitzen, die den ganzen Zelleib umgibt, und auch die Gründe angegeben, warum die Zell. membran bei dem färberischen Nachweis nur als kreisförmige Linie erscheint.

1) Protoplasma, Bd. 8, Heft 4 . 